University of Nebraska - Lincoln

DigitalCommons@University of Nebraska - Lincoln

Faculty Papers and Publications in Animal

Science

Animal Science Department

April 1981

\title{
GENETIC AND PHENOTYPIC RELATIONSHIPS BETWEEN \\ PUBERTAL AND GROWTH CHARACTERISTICS OF GILTS
}

L. K. Hutchens

Oklahoma State University, Stillwater

R. L. Hintz

Oklahoma State University, Stillwater

R. K. Johnson

University of Nebraska-Lincoln, rjohnson5@unl.edu

Follow this and additional works at: https://digitalcommons.unl.edu/animalscifacpub

Part of the Animal Sciences Commons

Hutchens, L. K.; Hintz, R. L.; and Johnson, R. K., "GENETIC AND PHENOTYPIC RELATIONSHIPS BETWEEN PUBERTAL AND GROWTH CHARACTERISTICS OF GILTS" (1981). Faculty Papers and Publications in Animal Science. 22.

https://digitalcommons.unl.edu/animalscifacpub/22

This Article is brought to you for free and open access by the Animal Science Department at DigitalCommons@University of Nebraska - Lincoln. It has been accepted for inclusion in Faculty Papers and Publications in Animal Science by an authorized administrator of DigitalCommons@University of Nebraska - Lincoln. 


\title{
GENETIC AND PHENOTYPIC RELATIONSHIPS BETWEEN PUBERTAL AND GROWTH CHARACTERISTICS OF GILTS ${ }^{1}$
}

\author{
L. K. Hutchens ${ }^{2}$, R. L. Hintz ${ }^{2}$ and R. K. Johnson ${ }^{3}$ \\ Oklaboma State University, Stillwater 74078
}

\section{Summary}

Data on 737 crossbred and purebred gilts were used to obtain heritability estimates for age at puberty (AGEPUB) and weight at puberty (WTPUB) and their genetic and phenotypic correlations with birth weight (BW), weaning weight (WW), postweaning daily gain (ADG), adjusted age at $90.7 \mathrm{~kg}$ (AGE) and adjusted backfat at $90.7 \mathrm{~kg}(\mathrm{BF})$. The heritability estimates for AGEPUB were low to moderate (.19 and .40, based upon paternal and maternal half-sib estimates, respectively.) The genetic $\left(r_{g}\right)$ and phenotypic $\left(r_{p}\right)$ correlations between AGEPUB and BW $\left(r_{g}=-.07 ; r_{p}=-.09\right)$, WW $\left(\mathrm{r}_{\mathrm{g}}=-.25 ; \mathrm{r}_{\mathrm{p}}=-.19\right)$, ADG $\left(\mathrm{r}_{\mathrm{g}}=-.38 ; \mathrm{r}_{\mathrm{p}}=\right.$ $-.34)$ and AGE $\left(r_{g}=.56 ; r_{p}=.38\right)$ were favorable. The genetic and phenotypic correlations between AGEPUB and BF were .27 and .01 , respectively.

(Key Words: Puberty, Swine, Heritabilities, Genetic Correlations, Growth.)

\section{Introduction}

The cost of developing replacement gilts will be reduced by decreasing age at puberty because gilts can be brought into production at an earlier age. Current selection practices emphasize increased growth rate and decreased backfat thickness, and thus, the magnitude and direction of the correlated response of age of puberty are of interest. The purpose of this study was to estimate the heritability of age at puberty and the genetic and phenotypic correlations of age at puberty with growth characteristics.

\footnotetext{
${ }^{1}$ Journal Article 3829 of the Agr. Exp. Sta., Oklahoma State Univ., Stillwater 74078.

${ }^{2}$ Anim. Sci. Dept.

${ }^{3}$ Present address: Anim. Sci. Dept., Univ. of Nebraska, Lincoln 68583 .
}

\section{Materials and Methods}

Data were collected on 819 purebred and crossbred gilts ( 33 sire and 131 dam groups) produced in a four-breed diallel mating system involving Duroc, Yorkshire, Spot and Landrace breeds. Each sire was mated at random to at least one dam of each breed. At least one sire of each breed was replaced each season. Gilts were born during the fall months of 1976 and 1977 and the spring months of 1977 and 1978. Farrowing took place in a central confinement building. One to 2 weeks later, gilts were moved either to pasture lots with three or four litters per lot or to an open-front confinement building with one litter per pen. Creep fed was made available to gilts at 3 week of age and litters were weaned at 6 weeks. At approximately 8 weeks of age, gilts were randomly assigned within litter to be fed either in an open-front confinement building (10 gilts per pen) adjacent to at least one pen of littermate boars or in pasture lots (approximately 50 per lot) along with littermate barrows for a gain test (two to $\mathbf{1 2}$ gilts per breed grou pmanagement regimen-season-year subclass).

All gilts were fed a $14 \%$ protein corn- or milo-based diet during the gain test. Gilts were removed from test on a weekly basis at approximately 90.7 kilograms. They were then probed for backfat, placed together in pasture lots and fed daily 1.8 to $2.2 \mathrm{~kg}$ of a $15 \%$ protein diet.

Puberty was defined as the first detected estrus, indicated by a standing response to a teaser boar. Average age when estrus detection began ranged from 163.5 to 172.9 days for the various breed groups. The distribution of age at puberty approximated a normal distribution, because $66.4,95.1$ and $99.6 \%$ of the records were within 1,2 and 3 standard deviations of the overall mean, respectively. After the gilts were placed in pasture lots (approximately 30 per lot), tests for estrus were started on a daily 
basis by exposure to teaser boars for 15 to 30 minutes. Tests for estrus were continued each season until the youngest gilt was at least 219 days of age. Eighty-two gilts were not detected in estrus, and they were not used in the analysis. These gilts either were slow to express estrus, were not observed in estrus or might never have cycled. Data used in the analysis consisted of information on gilts from 32 sire and 128 dam groups.

Birth weights were taken within $12 \mathrm{hr}$ of farrowing, and weaning weights were adjusted to a 42-day basis. The age at which gilts came off gair test was adjusted to a $90.7-\mathrm{kg}$ basis. Average daily gain was measured as the actual rate of gain during the gain test. The average of the backfat measurements taken at the shoulder, loin and rump (approximately $4 \mathrm{~cm}$ from the midline) was adjusted to a $90.7 \cdot \mathrm{kg}$ basis. The actual age and weight were recorded when gilts reached first detected estrus.

The experiment was conducted primarily for the purpose of breed evaluation. The sires sampled for each breed were selected on the basis of the National Swine Improvement Federation Test Station index of growth and backfat (Hubbard, 1976). Replacement gilts were selected from within herd on the basis of a similar index.

The following linear model was assumed:

$$
\mathrm{Y}=\mathrm{X} \beta+\mathrm{Z}_{1} \mathrm{~s}+\mathrm{Z}_{2} \mathrm{~d}+\mathrm{e}
$$

where

$\mathbf{Y}$ is a vector of observations;

$\mathbf{X}$ is a known design matrix;

$\beta$ is a vector of breed-of-sire effects, breedof-dam effects, season effects, year effects, management during gain test effects, breedof-sire $x$ breed-of-dam effects, breed-of-sire $x$ management effects, breed-of-dam $x$ year effects, breed-of-dam $\times$ management effects, year $x$ season effects, management $x$ season effects, breed-of-sire $x$ breed-of-dam $x$ management effects and breed-of-sire $x$ breed of dam $x$ year effects and a common constant $u$;

$Z_{1}$ is a known design matrix;

$s$ is a vector of one-half the additive genetic effects of the sires having multivariate distribution with mean zero and a nonsingular variancecovariance matrix $G_{1}$;

$Z_{2}$ is a known design matrix;

$\mathbf{d}$ is a vector of one-half the additive genetic effects and any maternal effects of the dam having a multivariate distribution with mean zero and a nonsingular variance-covariance matrix $G_{2}$; e is a vector of residual effects including environmental and other genetic effects having a multivariate distribution with mean zero, and variance-covariance matrix $R, s$, $\mathbf{d}$ and $e$ are mutually uncorrelated.

The decision as to which interactions would be included in the model for each trait was based on the results of preliminary analyses. Inclusion of all possible interactions would have created a sparce matrix. Litter size was not included as a covariate in the model, because adjustment of the data for litter sizc weaned did not appreciably alter the heritability and correlation estimates (maximum change of .02). It was assumed that $\mathrm{R}=\mathrm{I}^{2} \sigma_{\mathrm{e}}$, where $\mathrm{I}$ is an identity matrix with order equal to the number or records, which implies that the elements of $e$ are uncorrelated and that all records have common variance, $\sigma_{\mathrm{e}}^{2}$. The variance-covariance matrix $G_{1}$ was assumed to be $1 \sigma^{2}{ }_{s}$, where $I$ is an identity matrix with order equal to the number of sires and $\sigma^{2}$ is equal to one-fourth the additive genetic variance. The variancecovariance matrix $\mathbf{G}_{2}$ was assumed to be $\mathrm{Io}^{2}{ }_{\mathrm{d}}$, where $I$ is an identity matrix with order equal to the number of dams and $\sigma_{d}^{2}$ is equal to one-fourth the additive genetic variance plus any maternal variation. Theoretically, covariances among half-sibs are not the same for purebreds and crossbreds. Also, genetic parameters may not be the same for gilts raised on pasture and gilts raised in confinement. In this study, numbers were not large enough for either hypothesis to be tested.

Henderson's (1953) Method 3, often called the "fitting constants method," was used to obtain unbiased estimates of the variance and covariance components. Heritability $\left(\mathrm{h}^{2}\right)$ estimates were obtained by the following equations:

$$
\begin{aligned}
& \hat{h}^{2}=4 \hat{\sigma}^{2}{ }_{s} /\left(\hat{\sigma}^{2}{ }_{s}+\hat{\sigma}^{2}{ }_{d}+\hat{\sigma}^{2}{ }_{\mathrm{e}}\right) \text { (paternal); } \\
& \hat{h}^{2}=4 \hat{\sigma}^{2}{ }_{\mathrm{d}} /\left(\hat{\sigma}_{\mathrm{s}}^{2}{ }_{\mathrm{s}}+\hat{\sigma}^{2}{ }_{\mathrm{d}}+\hat{\sigma}^{2}{ }_{\mathrm{e}}\right) \text { (maternal). }
\end{aligned}
$$

Approximate standard errors of the heritability estimates were obtained with an approximate formula (Swiger et al., 1964). Genetic correlations were calculated from sire variance and covariance components as follows:

$$
\hat{r}_{z}=\hat{\sigma}_{s_{x} s_{y}} / \sqrt{\hat{\sigma}^{2} s_{x} \hat{\sigma}^{2} s_{y}}
$$


where $\hat{\sigma}_{s_{x} s_{y}}$ represents the estimated covariance of trait $\mathrm{x}$ and $\mathrm{y}$ for sires, and $\sigma^{2} \mathrm{~s}_{\mathrm{x}}$ and $\sigma^{2}{ }_{\mathrm{s}_{\mathrm{y}}}$ represent the estimated sire components of variance for traits $x$ and $y$, respectively. Standard errors of the genetic correlations were not calculated, because the estimated standard errors for genetic correlations between age at puberty and the growth traits (correlations of major interest in this study) would have been biased upward on the basis of the magnitude of the heritabilities and number of animals involved (Van Vleck and Henderson, 1961). Phenotypic correlations were calculated from the sum of the variance and covariance components. Computer programs developed by R. L. Hintz (unpublished) were used for the analysis.

\section{Results and Discussion}

Heritabilities. The paternal half-sib heritability estimate for age at puberty was .19 (table 1). While this is not a high heritability, it does suggest that improvement can be made through selection. The estimate is lower than the weighted average (by number of offspring) of .34 for swine calculated by various methods (Reutzel and Sumption, 1968; Legault, 1973; Cunningham et al., 1974; Young et al., 1978).

The maternal half-sib heritability estimate for age at puberty was considerably larger than the paternal half-sib estimate (.40 vs .19). The dam component of variance included all of the maternal additive genetic variance, the covariance between direct and maternal additive effects and both the maternal dominance and maternal environmental variances. These were not included in the sire component of variance and four times their contributions would lead to differences between paternal and maternal estimates of heritability. A suggestion of possible maternal effects upon age at puberty would agree with other reports. The paternal half-sib estimate and the offspring-on-dam regression estimate were -.20 and .49 , respectively (Reutzel and Sumption, 1968). Variance components for dams were larger than variance components for sires for age at breeding (Reddy et al., 1958) and age at puberty (Legault, 1973). Furthermore, in studies by Dyck (1971) and Burger (1952), 49.0 and $53.5 \%$, of full sisters, respectively, reached puberty within a period of 5 days.

The paternal half-sib estimate for weight at puberty was .35 (table 1 ). This estimate agrees with a weighted average of .31 (Reutzel and Sumption, 1968; Legault, 1973; Young et al., 1978).

In general, heritability estimates for the growth traits were higher than those previously reported (Hutchens, 1980). Reasons for the higher estimates may be the differences in statistical models used, the differences in methods used (e.g., paternal half-sib versus regression of offspring on parent) and sampling error. However, we have no specific explanation as to why the heritability estimates for both weight and weaning weight were greater than 1.

Correlations. The genetic correlations of age at puberty with birth weight $(-.07)$, weaning weight $(-.25)$, postweaning daily gain $(-.38)$ and age at $90.7 \mathrm{~kg}(.56)$ increased in magnitude as the age at which growth was measured increased (table 2). The direction of the genetic correlations indicates that continued selection for growth rate would tend to decrease the age at puberty. Similar favorable genetic relationships of birth weight (-.14), weaning weight $(-.04)$ and postweaning daily gain $(-.33)$ with

TABLE 1. HERITABILITY ESTIMATES AND MEANS FOR PUBERTAL AND GROWTH CHARACTERISTICS AND THEIR STANDARD ERRORS

\begin{tabular}{lcrr}
\hline Trait & Paternal half sib & Maternal half sib & Mean \\
\hline AGEPUB, days & $.19 \pm .09$ & $.40 \pm .13$ & $190.9 \pm .80$ \\
WTPUB, kg & $.35 \pm .12$ & $.26 \pm .12$ & $94.2 \pm .37$ \\
BW, kg & $1.53 \pm .26$ & $.32 \pm .12$ & $1.5 \pm .01$ \\
WW, kg & $1.20 \pm .24$ & $.80 \pm .15$ & $11.8 \pm .10$ \\
ADG, kg & $.69 \pm .18$ & $.54 \pm .14$ & $.69 \pm .003$ \\
AGE, days & $.60 \pm .17$ & $.79 \pm .15$ & $170.0 \pm .38$ \\
BF, cm & $.51 \pm .15$ & $.55 \pm .14$ & $2.52 \pm .10$ \\
\hline
\end{tabular}

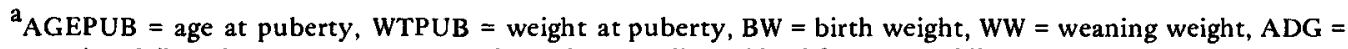
postweaning daily gain, $\mathrm{AGE}=$ age at $90.7 \mathrm{~kg}$ and $\mathrm{BF}=$ adjusted backfat at 90.7 kilograms.
} 


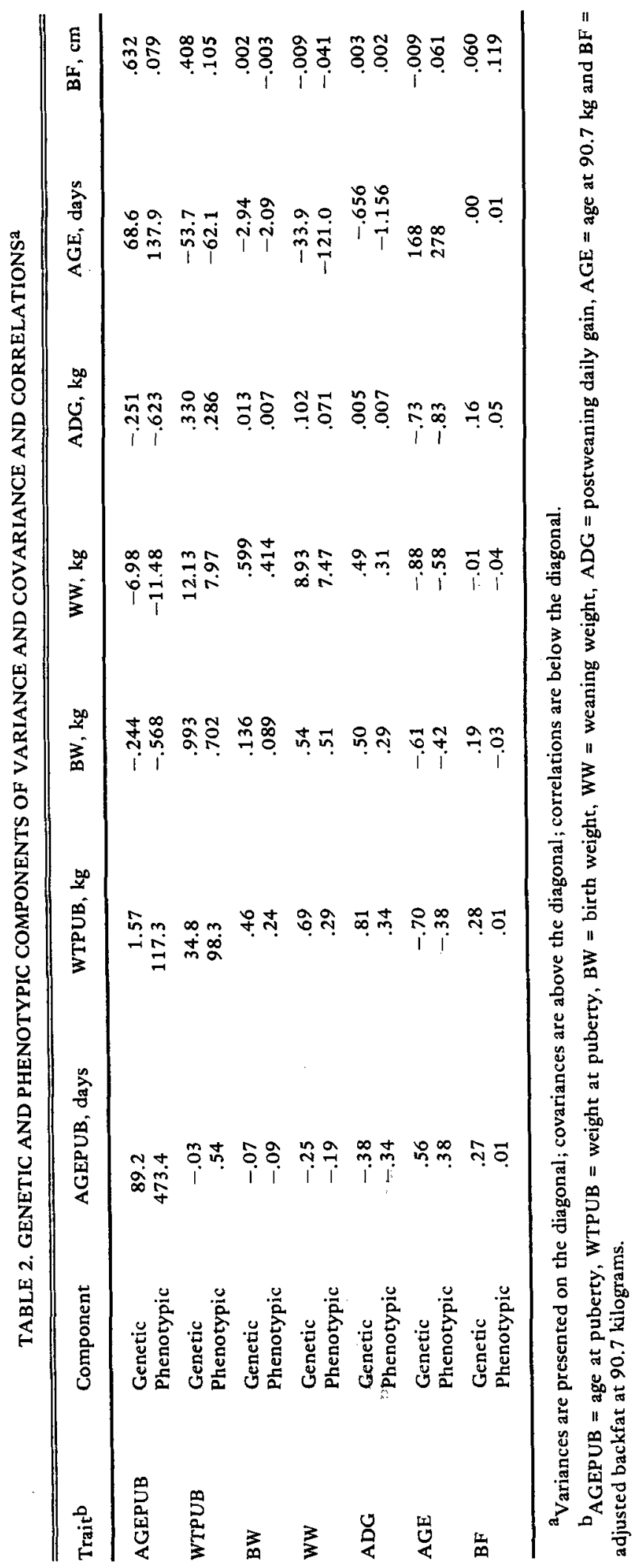


age at puberty have been reported (Young et al., 1978). However, an unfavorable genetic covariance between postweaning daily gain and age at puberty was reported by Reutzel and Sumption (1968). Other researchers estimating between-line correlations found that lines having the highest average 154-day weight tended to be the slowest to reach puberty, which may suggest a nonfavorable genetic relationship (Phillips and Zeller, 1943; Warnick et al., 1951). However, unless lines have been selected under similar environments and for similar objectives, between-line correlations may not reflect within-line genetic correlations.

The phenotypic correlations of age at puberty with birth weight $(-.09)$, weaning weight $(-.19)$, postweaning daily gain (-.34) and age at 90.7 $\mathrm{kg}(.38)$ also generally increased with the age at which growth was measured. The estimates between age at puberty and birth weight and weaning weight agree with the weighted averages from the literature, -.01 and -.12 , respectively (Hutchens, 1980). The phenotypic correlation between postweaning daily gain and age at puberty (-.34) was higher than the weighted average of -.17 (Hutchens, 1980). A possible explanation for the higher phenotypic correlation is that faster-growing gilts were exposed to boars at a younger age and, hence, could be detected in estrus earlier; however, this estimate is similar in magnitude to many of the phenotypic correlations reported between 154-day weight and age at puberty (Warnick et al., 1951; Robertson et al., 1951a,b; Self et al., 1955; Foote et al., 1956). Estimates from this investigation indicate that gilts with a faster growth rate would tend to reach puberty at a younger age.

The genetic correlation between age at puberty and backfat was low and positive (.27). This estimate is higher than the genetic correlation estimate of .00 reported by Young $e t$ al. (1978). If any genetic relationship exists between age at puberty and backfat, it appears to be low and positive. The phenotypic correlation between age at puberty and backfat was .01 , which is similar to the weighted average of .07 reported by Hutchens (1980). There appears to be little, if any phenotypic association between age at puberty and backfat.

The genetic correlations of growth traits with weight at puberty were consistently higher than those of growth traits with age at puberty, suggesting that weight at puberty is more closely related to growth than is age at puberty.
The genetic correlation estimates of weight at puberty with weaning weight and postweaning daily gain, .69 and .81 , respectively, fall between those reported by Young et al. (1978), .01 and .19 , respectively, and Reutzel and Sumption (1968), .70 and 1.01, respectively. The greatest correlation was with growth measured later in life.

Estimates of the phenotypic correlations of weight at puberty with birth weight, weaning weight, postweaning daily gain and age at $90.7 \mathrm{~kg}$ were low to moderate $(.24, .29, .34$ and -.38 , respectively). These values agree quite well with weighted averages of $.27, .28$ and .39 for the correlation of weight at puberty, birth weight, weaning weight and postweaning daily gain, respectively (Reutzel and Sumption, 1968; Young et al., 1978). Thus, gilts with a faster growth rate would tend to be heavier at puberty.

The phenotypic correlation between weight at puberty and backfat was .01 , indicating no phenotypic association between the two traits. The weighted average of two estimates reported in the literature is -.12 (Reutzel and Sumption, 1968; Young et al., 1978).

The genetic correlation between age at puberty and weight at puberty was -.03 . This value disagrees with that of .90 reported by Young et al. (1978). The phenotypic correlation between age at puberty and weight at puberty was .54 , which agrees with the weighted average of .65 reported by Hutchens (1980). This suggests that gilts reaching puberty at later ages would also be expected to be heavier at puberty.

\section{Conclusions}

The heritability estimates indicate that age at puberty is low to moderately heritable and that age at puberty may be reduced through selection. However, the estimated genetic correlations with growth in this study indicate that continual selection for growth rate would result in a correlated decrease in age at puberty. These data also suggest a low, favorable genetic association between age at puberty and backfat.

\section{Literature Cited}

Burger, J. F. 1952. Sex physiology of pigs. Onderstepoort J. Vet. Res. (Suppl.) 2:218.

Cunningham, P. J., G. H. Naber, D. R. Zimmerman and E. R. Peo, Jr. 1974. Influence of nutritional regime on age at puberty in gilts. J. Anim. Sci. $39: 63$

Dyck, G. W. 1971. Puberty, postweaning estrus and 
estrous cycle length in Yorkshire and Lacombe swine. Can J. Anim. Sci. 51:135.

Foote, W. C., D. P. Waldorf, A. B. Chapman, H. L. Self, R. H. Grummer and L. E. Casida. 1956. Age at puberty of gilts produced by different systems of mating. J. Anim. Sci. 15:959.

Henderson, C. R. 1953. Estimation of variance and covariance components. Biometrics 9:226.

Hubbard, D. D. 1976. Guidelines for uniform swine improvement standards. Program A, 01157 USDA Extension Service.

Hutchens, L. K. 1980. Age and weight of puberty of purebred and crossbred gilts involving four breeds and their genetic and phenotypic relationship with growth characteristics. M.S. Thesis. Oklahoma State Univ., Stillwater.

Legault, C. 1973. Genetic analysis of sexual precocity, ovulation and number of embryos in the sow: Heritability, effect of heterosis. Journees de la Recherche Porcine en France, p. 147.

Phillips, R. W. and J. H. Zeller. 1943. Sexual development in small and large types of swine. Anat. Rec. $85: 387$.

Reddy, V. B., J. Lasley and D. T. Mayer. 1958. Genetic aspects of reproduction in swine. Missouri Agr. Exp. Sta. Res. Bull. 666.

Reutzel, L. F. and L. J. Sumption. 1968. Genetic and phenotypic relationships involving age at puberty and growth rate of gilts. J. Anim. Sci. 27:27.
Robertson, G. L., L. E. Casida, R. H. Grummer and A. B. Chapman. 1951a. Some feeding and management factors affecting age at puberty and related phenomena in Chester White and Poland China gilts. J. Anim. Sci. 10:841.

Robertson, G. L., R. H. Grummer, L. E. Casida and A. B. Chapman. $1951 \mathrm{~b}$. Age at puberty and related phenomena in outbred Chester White and Poland China gilts. J. Anim. Sci. 10:647.

Self, H. L., R. H. Grummer and L. E. Casida. 1955. The effects of various sequences of full and limited feeding on the reproductive phenomena in Chester White and Poland China gilts. J. Anim. Sci. 14:573.

Swiger, L. A., W. R. Harvey, D. O. Everson and K. E. Gregory. 1964. The variance of interclass correlation involving groups with one observation. Biometrics 20:818.

Van Vleck, L. D. and C. R. Henderson. 1961. Empirical sampling estimates of genetic correlations. Biometrics 17:359.

Warnick, A. C., E. L. Wiggins, L. E. Casida, R. V. Grummer and A. B. Chapman. 1951. Variation in puberty phenomena in inbred gilts. J. Anim. Sci. 10:479.

Young, L. D., R. A. Pumfrey, P. J. Cunningham and D. R. Zimmerman. 1978. Heritabilities and genetic and phenotypic correlations for prebreeding traits and principal components. J. Anim. Sci. $46: 937$. 